\title{
An Analysis of the Effectiveness of Early Warning in Conflict Prevention in the African Great Lakes Region
}

\author{
Eric Junior Wagobera \\ Department of Humanities, School of Social Sciences, Mount Kenya University, Nairobi, Kenya.
}

\begin{abstract}
How to cite this paper: Eric Junior Wagobera. (2020) An Analysis of the Effectiveness of Early Warning in Conflict Prevention in the African Great Lakes Region. International Journal of Humanities, Arts and Social Science, 4(1), 29-34.

DOI: $10.26855 /$ jhass.2020.01.004
\end{abstract}

Received: March 13, 2020

Accepted: April 6, 2020

Published: April 13, 2020

*Corresponding author: Eric Junior Wagobera, School of Social Sciences, Mount Kenya University, Nairobi, Kenya.

Email: wagobera@outlook.com

\begin{abstract}
This paper seeks to provide a holistic overview of the effectiveness of early warning mechanisms in the African Great Lakes region. It analyzes the current state of conflict early warning in countries that have experienced erratic large-scale conflicts such as Rwanda, South Sudan, and the eastern region of D.R. Congo. The objective was to determine how effective has the early warning mechanism been in preventing conflicts within the African Great Lakes region. According to the research findings, early warning has to a considerable extent been ineffective due to its weak structures which explains the persistent conflicts such as those in South Sudan and the war-torn eastern D.R. Congo despite the numerous global interventions. The failure is largely attributed to the incompatibility of the existing early warning mechanisms to the region's relentless nature of conflicts, and the reluctance by the policymakers to act swiftly even when the early warning signs are apparently clear.
\end{abstract}

\section{Keywords}

Early Warning, Conflict Prevention, African Great Lakes, Civil Wars, East Africa

Conflict prevention in the African Great Lakes region remains a top priority of all concerned stakeholders but the persistent nature of the conflicts in the region casts doubt on the possibility of sustainable peace in the region. Early warning is one of the commonly-used mechanisms to prevent conflicts whose effectiveness in the region has not been previously determined.

\section{Background}

Early warning in conflict prevention facilitates the prediction or forecasting of potential conflict outbreak through the recognition of early violence escalation with an aim of preventing both the outbreak and a further escalation of violence to save human lives (Engel, 2018). Conflict early warning emerged on the international policy agenda after the end of Cold War, and since then, different approaches have been developed for conflict prediction and monitoring (Holm, 2019). Notably, conflict early warning became the focus of the post-Yom Kippur and Falklands Wars of 1973 and 1982 respectively with debates raging among political scientists over the absence of early warning mechanisms since many stakeholders, including the United Nations were taken by surprise (Jeong, 2017).

\section{Early Warning in the Great Lakes}




\subsection{Conflict Early Warning in Rwanda}

The horrors of the 1994 Rwandan genocide incited renewed interest across the globe regarding the role and effectiveness of early warning mechanisms. It is generally believed that the failure to heed to early warning signs gave way to the mass slaughter in which more than 800,000 people were killed in 100 days (Levinger, 2016). Later, it was observed that "the consequences of failing to heed the warning signs were monumentally horrifying" as it was also revealed that the United Nations peacekeeping force in Rwanda at the time had appealed in vain for the world to take early actions before it was too late (United Nations, 2014). Accordingly, early warning was not effective enough to prevent the 1994 Rwandan genocide, mainly "because policymakers perceived it as a civil war" which prevented representatives at the time to call it a genocide (Levinger, 2016).

\subsection{Conflict Early Warning in South Sudan}

There were no known early warning mechanisms put in place in South Sudan until recently when major stakeholders started conducting training on conflict early warning and response which was the first of its kind in the country (UNDP, 2019). The absence of early warning in South Sudan has given way to constant conflict outbreaks in which millions of lives have been lost in identity-based conflicts.

Despite a series of peace agreements, conflicts were on a steep rise which necessitated the reinforcement of early warning mechanisms among the local communities. It was further noted that access restrictions in South Sudan seriously impeded the ability of international actors and local civil society organizations to undertake monitoring activities in conflict areas (UNDP, 2019). Furthermore, it was noted that early warning information was ineffective as it never reached the concerned authorities due to the remote nature of the conflict zones (CCCR, 2019).

\subsection{Conflict Early Warning in Eastern D.R. Congo}

Due to the increase in violence and conflicts in the eastern region of the Democratic Republic of the Congo, several civil society organizations have taken the lead in the operationalization of early warning mechanisms in the area. After a series of attacks by the various rebel groups on local communities in Beni, North Kivu province, the ABA Rule of Law Initiative worked with local authorities to form civil protection units "to empower community members to report security threats and facilitate government response" (ABA, 2016). In its first three months, the initiative received at least 47 reports of violence and security threats from community observers which helped to thwart attacks on civilians.

\section{Problem Statement}

The African Great Lakes region has for decades been embroiled in civil wars, and political instabilities (Del Castillo, 2017). Such conflicts have brought about untold suffering in the form of poverty, refugee crises resulting in internally displaced persons (Khadiagala, 2017). Being a prominent conflict prevention mechanism in the region, the effectiveness of early warning needed to be understood in the backdrop of the protracted conflicts in South Sudan and eastern D. R. Congo (Engel, 2018). Accordingly, this study was undertaken to find out whether early warning has been effective in preventing conflicts within the region that is regarded as the most volatile in Africa.

\section{Methodology}

The study was carried out using the mixed methods research and participants were drawn from countries that have previously experienced some form of conflicts such as Rwanda, the Democratic Republic of Congo, South Sudan, and Burundi. All participants had proven experience working with civil society organizations, intergovernmental and non-governmental bodies that directly or indirectly work for peace restoration in the region. Data were collected using questionnaires that were distributed to seventy-one participants selected using the convenience non-probability sampling.

\section{Literature Review}

\subsection{The State of Early Warning Mechanisms}


Early warning is only helpful if it converts to early action and hence the international community and regional bodies need to step up and address the loopholes that hinder its effectiveness in Africa's conflict hotspots (Williams, 2016). However, there is no known mutually agreed-upon blueprint to guide regional bodies like IGAD and EAC in making early warning mechanisms work in the African Great Lakes region.

Often times, it is maintained that the current early warning mechanisms are unadaptable to the unpredictable nature of conflicts in the region since they tend to be volatile as they can ignite and halt abruptly, intensify and spread without prior warning (Kamatsiko, 2017). One scholar said that for early warning mechanisms to be effective in the Great Lakes region, the supporting mechanisms should be fully acceptable by all concerned stakeholders (Greene and Sentongo, 2019). However, Kamatsiko (2017) cautions that conflict early warning does not have to overly be accustomed to the rigid institutional frameworks to conform to the nature of conflicts.

\subsection{Gaps in Early Warning Mechanisms}

Other scholars allude to the lack of cooperation between states and the international bodies when it comes to conflict prevention due to claims of interference by one party against the other which impedes conflict early warning efforts (Greene and Sentongo, 2019). It was further observed that early warning mechanisms tend to scale down after the critical moments of conflicts have lapsed and thus making timely conflict prevention untenable (Greene and Sentongo, 2019). Kamatsiko (2017) adds that strong foundations are needed to make early warning tenable in the long term which may also facilitate the addressing of the root causes of conflicts as the approach is cost-effective, however, this requires the provision of continuous monitoring and financial investments to deliver desired results.

The scholars, however, do not offer guidelines for financing conflict early warning mechanisms, but the common norm has always been reliance on voluntary contributions by member states, and funding by international bodies. The mechanism of early warning as part of conflict prevention is not all about detecting and limiting conflicts but also about several thresholds in their development early in advance, at a time when they are focused on the underlying sources of disputes (Greene and Sentongo, 2019).

\subsection{Making Early Warning Work}

One scholar looks at conflict early warning as acting early in advance to prevent conflicts from escalating by detecting tensions and reducing the possibility of war (Engel, 2018). He further posited that early warning mechanisms need to be on standby and terms it as 'sounding alarm bells at the right time in an appropriate and salutary manner'. Engel insisted on the need to acquire quality intelligence in a timely and reliable form which can help to diffuse tension, and where possible, involve by third parties such as NGOs.

Making early warning work requires a constant monitoring of trivial issues that affect the community as a whole, emphasizing the lost opportunities such as unfair government policies, environmental degradation, increased frustrations due to the deteriorating nature of economic conditions, and unusual population trends (Subedi, 2017). They also reveal a missing link between early warning and effective and timely response as they attributed the gaps to the disorganized approaches used to gather, sort, and analyze data on the rapid changes in global events and the limited resources for carrying out early warning.

The work of Subedi (2017) remains relevant as it emphasizes the importance of crucial principles of conflict early warning but their study does not highlight how early warning can work hand in hand with other critical conflict prevention approaches alike neutrality, trust, and preventive deployment, despite outlining complex conditions in the international systems such as economic factors and the limited resources as hindrances to effective conflict prevention and containment.

\section{Findings}

The study sought to determine the effectiveness of early warning in conflict prevention within the Great Lakes region, and the key question put forward was; Do you think early warning has been effective in preventing conflicts in the African Great Lakes region? As shown in Table 1, respondents selected their responses based on their level of agreeability to the statement "Early warning has been effective in preventing conflicts in the African Great Lakes region."

Accordingly, those who strongly disagreed are twelve percent; those who disagreed are twenty-five percent, the neutral ones were thirty-two percent, those who agreed were at twenty-three percent, whereas those who strongly 
disagreed were at eight percent. Besides being neutral, the findings show that a relative majority of respondents do not agree that early warning has been effective in the African Great Lakes region.

Table 1. Effectiveness of Early Warning in African Great Lakes

\begin{tabular}{lcc}
\hline Selection & $\underline{\text { Tally }}$ & Percentage (\%) \\
\hline Strongly disagree & 09 & 12 \\
Disagree & 18 & 25 \\
Neutral & 23 & 32 \\
Agree & 16 & 23 \\
Strongly agree & 05 & 8 \\
Total & 71 & 100 \\
\hline
\end{tabular}

Respondents were further asked to give reasons for their selection above. A variety of reasons were given to portray their understanding and interpretation regarding the effectiveness of early warning as a preventive diplomacy mechanism in the African Great Lakes region. Respondents who disagreed said that given the different nature of conflicts in the region, they have been recurring for a long time despite the continuous use of early warning mechanisms, which implies that early warning has not been sustainable in the region. Another respondent said that early warning mechanisms give timely occurrence of conflicts in different states within the region, but mostly the response has been inadequate due to the wrong assessments of conflicts.

It was noted that early warning might give perpetrators of conflict more room to come up with other ways of conflicting since stakeholders may not necessarily abide by the warnings. Others cited the lack of implementation spirit for acting on the early warning signs saying that early warning only works in regions where leaders are willing to overcome their differences to put peacebuilding ahead of their issues. People in the region have continued to fight despite being warned. Others said that early warning is not enough, and that other measures such as alternative dispute resolution, outright peacebuilding, and conflict prevention should instead be prioritized in developing mechanisms for averting conflicts before they materialize. One respondent observed that despite the early warnings, there are still more active conflicts since early warning is not designed to address the causes of conflicts in the region.

Those who agreed attested to witnessing the success of early warning, notably when potential conflicts were averted after the caution was heeded to which significantly saved millions of lives and property. Others said that early warning makes people alert, which has enabled the quick addressing of pertinent issues that could have otherwise led to conflict outbreaks citing the example of the 2013 Kenya general elections where post-election violence was minimized due to early warning.

Others said that early warning had helped conflict perpetrators to fully understand the repercussions of their actions and, hence avoiding conflicts. Those who strongly agreed said that early warning creates time for parties to come together and reflect on the consequences of their actions at the negotiation table. Another one said that through intelligence, states have been able to foretell conflict situations some of which have successfully been prevented, but some have been ignored thus leading to disastrous catastrophes.

Neutral respondents who were neutral conferred that they have not witnessed any early warning being applied in the context of conflicts within the region and therefore cannot be conclusive on an issue they are not aware of. Another one said that early warning is always there but still more genuine efforts that surpass just warnings are needed on the ground. By nature, people in the region do not care to listen and act upon the early warning given to them.

Those who strongly disagreed said that early warning has not been adequate since, by nature, policymakers in the region are known to rush into last-minute approaches as a response to potential conflicts. A typical example was given of the 2007/8 post-election violence when early warning signs were clear that violence was likely, but no one acted upon them. Some of these respondents also noted that early warning is sometimes a wastage of time and resources since, in the end it will not achieve anything. Others said that the on-and-off conflicts are evidence of the failure of early warning. Another one blamed the polarizing effect of the region's media which keeps fanning conflicts by ignoring to inform people of the early warning signs to a conflict. 


\section{Discussion}

Early warning is a crucial preventive diplomacy ingredient in conflict prevention. Not only does it facilitate the identification of possible signs of conflicts, according to the findings, it also creates awareness of both the unknown and ignored issues of contention. One scholar reiterated the need for identifying conflicts well early enough to prevent the start and escalation of conflicts (Del Castillo, 2017). However, looking at the response scale to the question of whether early warning has been effective in the African Great Lakes region, it can be inferred that the agreeability side has a fewer selection, but the disagreeability side has more.

It implies that from the responses given, early warning has been largely ineffective at preventing conflict outbreaks within the region which implies its weakness. It may not come as a surprise to diplomacy scholars and practitioners alike since early warning structures in the region are known to be either non-existent or very weak. Some have been in existence but largely futile; otherwise people would not be complaining about the region's unending conflicts such as the ongoing South Sudan civil war.

Whereas early warning mechanisms need to be focused on identifying threats in a timely and effective manner, which has not been the case in the African Great Lakes region. Early warning has not been appropriately tailored to deal with the intriguing nature of conflicts in the region mainly because the early warning elements are western-themed thus rendered useless in the African Great Lakes region. Therefore, early warning needs to be geared towards addressing the root causes of the region's specific conflicts before it is followed by violence.

Furthermore, agencies that work to prevent conflicts in the region have all along used the wrong approaches in early warning, as they have done little to inspire the implementation spirit of acting on the early signs of conflicts. Similarly, the ideology of last-minute early warning may have to be disregarded because early warning has to be operational at all times and never as a last resort tool when conflicts have broken out because it will not serve the intended purpose. Now that the weak spots have been identified, the region's preventive diplomacy policymakers such as diplomats, peacemakers, and CSOs may have to devise the appropriate measures to seal the identified gaps in early warning within the region.

\section{Conclusion}

Early warning has been successful only to a certain extent and the main reason is that strong policies are still missing to effectively implement these mechanisms to the region's conflicts, which are distinctive in their nature compared to conflicts in the other parts of the world. The inclination to act on the cautionary signs is still lacking among the region's policymakers. The main weakness is that the existing early warning mechanisms are not tailor-made to fit the complex dynamics of the African Great Lakes region's conflicts, and even though they worked elsewhere. Due to the remoteness of conflict-prone areas, at times it is impossible to detect and report conflicts early in time.

In other areas, early warning has failed to take into consideration the deviating nature of conflicts, but the critical fact is that policymakers have always been cautioned on the signs of impending conflicts, but they failed to take them seriously. It can as well be understood that the renewed conflicts in the region may be blamed on this loophole - the failure to detect conflicts before they break out. A breakdown study is recommended in any single country to look at it based on its own circumstances, such as research on the effectiveness of early warning in conflict prevention in active conflict hotspots such as D.R. Congo, Rwanda, or South Sudan.

\section{Declaration of Interest Statement}

The Author declares that there is no conflict of interest.

\section{References}

ABA. (2016). Early warning system thwarts attacks on civilians. Chicago: American Bar Association.

CCCR. (2019). Strengthening civil society early warning and advocacy on identity-based violence in South Sudan. London: Ceasefire Center for Civillian Rights.

Del Castillo, G. (2017). Obstacles to peacebuilding. Taylor \& Francis.

Engel, U. (2018). Early warning and conflict prevention. The Routledge Handbook of Transregional Studies, 573-581.

Engel, U. (2018). Knowledge production on conflict early warning at the African Union. South African Journal of International Affairs, 25(1), 117-132. 
Greene, A. L. and Sentongo, A. (2019). Assessing National Mechanisms for Atrocity Prevention in Africa's Great Lakes Region. Journal of Peacebuilding \& Development, 14(2), 193-205.

Holm, H. H. (2019). Whose world order?: uneven globalization and the end of the Cold War. Routledge.

Jeong, H. W. (2017). Peace and conflict studies: An introduction. Taylor \& Francis.

Kamatsiko, V. V. (2017). Civil society organizations, Africa's Great Lakes Region conflict, and attempts at regional peacebuilding. Journal of Civil Society, 13(1), 54-70.

Khadiagala, G. M. (2017). Conclusions: Reversing the Spirals of Conflict and Instability in the Great Lakes Region. In War and Peace in Africa's Great Lakes Region (pp. 137-143). Palgrave Macmillan, Cham.

Levinger, M. (2016). Why the US Government Failed to Anticipate the Rwandan Genocide of 1994: Lessons for Early Warning and Prevention. Genocide Studies and Prevention: An International Journal, 9(3), 6.

Subedi, D. B. (2017). Early warning and response for preventing radicalization and violent extremism. Peace Review, 29(2), 135-143.

UNDP. (2019). Stakeholders seek to strengthen conflict early warning and early response systems in South Sudan. Juba: United Nations Development Programme.

United Nations. (2014). World must heed early warning signs to prevent genocide, UN is told. New York: UN News. Retrieved from https://news.un.org/en/story/2014/01/549772-world-must-heed-early-warning-signs-prevent-genocide-un-told

Williams, P. D. (2016). War and conflict in Africa. John Wiley \& Sons. 